N. Thomsen, et al., Int. J. of Energy Prod. \& Mgmt., Vol. 4, No. 1 (2019) 28-39

\title{
A SUSTAINABLE PROTOTYPE FOR RENEWABLE ENERGY: OPTIMIZED PRIME-POWER GENERATOR SOLAR ARRAY REPLACEMENT
}

\author{
NATHAN THOMSEN, TORREY WAGNER, ANDREW HOISINGTON \& STEVEN SCHULDT \\ Department of Systems Engineering and Management, Air Force Institute of Technology, \\ Wright-Patterson Air Force Base, USA.
}

\begin{abstract}
Remote locations such as disaster relief camps, isolated arctic communities, and military forward operating bases are disconnected from traditional power grids forcing them to rely on diesel generators with a total installed capacity of 10,000 MW worldwide. The generators require a constant resupply of fuel, resulting in increased operating costs, negative environmental impacts, and challenging fuel logistics. To enhance remote site sustainability, planners can develop stand-alone photovoltaic-battery systems to replace existing prime power generators. This paper presents the development of a novel cost-performance model capable of optimizing solar array and Li-ion battery storage size by generating tradeoffs between minimizing initial system cost and maximizing power reliability. A case study for the replacement of an $800 \mathrm{~kW}$ generator, the US Air Force's standard for prime power at deployed locations, was analyzed to demonstrate the model and its capabilities. A MATLAB model, simulating one year of solar data, was used to generate an optimized solution to minimize initial cost while providing over $99 \%$ reliability. Replacing a single diesel generator would result in a savings of 1.9 million liters of fuel, eliminating 100 fuel tanker truck deliveries annually. The distinctive capabilities of this model enable designers to enhance environmental, economic, and operational sustainability of remote locations by creating energy self-sufficient sites, which can operate indefinitely without the need for resupply.

Keywords: Battery, Diesel generator, Energy storage, Isolated sites, Optimization, Photovoltaic, Renewable energy, Solar array, Stand-alone.
\end{abstract}

\section{INTRODUCTION}

At locations around the world, many isolated sites lack access to reliable power grids, requiring them to rely on diesel generators in order to produce power. Examples of these locations include developing nation villages, disaster relief camps, isolated arctic communities, and military forward operating bases (FOBs). While as many as 1.2 billion people still do not have any access to power, over 10,000 MW of off-grid diesel generators are presently installed at other isolated locations [1]. Locations that operate using generators face challenges including the constant need for fuel resupply, local air and noise pollution, and regular maintenance to keep these generators running. The negative aspects of diesel power generation make these remote locations ideal candidates for the use of renewable energy. While small-scale examples of renewable power exist, renewable energy has yet to enter substantial service for prime power applications at remote sites with greater than $100 \mathrm{~kW}$ of capacity [1].

One such type of remote location is military FOBs, which range in occupancy from a few hundred to a few thousand personnel. These isolated bases form an ideal case study for potential renewables. To power nearly all FOBs, the United States Department of Defense (DoD) currently uses prime power plants, consisting of several large diesel generators. The operating cost of diesel generation is higher than traditional domestic grid power. A conservative estimate puts generator power for US FOBs at $\$ 0.17 / \mathrm{kWh}$ vs. $\$ 0.10 / \mathrm{kWh}$ grid production based on a diesel cost of $\$ 0.44 / \mathrm{L}$ (\$1.70/gal) [2]. This estimate does not account for the fully burdened cost of fuel, which includes the expense of transportation and logistics. DoD estimates on this quantity start at a minimum of $\$ 4 / \mathrm{L}(\$ 15 / \mathrm{gal})$ according to the Government 
Accountability Office [3]. Therefore, the actual cost for power at FOBs is likely close to $\$ 1.50 / \mathrm{kWh}$. Generator maintenance provides an additional cost burden, requiring a dedicated team of technicians on standby at all times [2].

Furthermore, the logistics chain required to keep these FOBs supplied with fuel is an issue of great concern. Massive quantities of fuel must be transported via air, sea, or land-except in rare cases where pipelines are available. For FOBs not collocated with a port, land convoys are the only viable option since airlift of fuel is cost prohibitive [4]. Fuel convoys are dangerous, requiring troops or contractors to travel hundreds of miles through uncontrolled territory vulnerable to attack. One study noted that in Afghanistan there is one additional fatality per each 24 fuel convoys [5]. These convoys are also vulnerable to embargos, border closures, corruption, local supply issues, and bridge and road collapses. Because of this, current FOB energy resiliency is low. Due to the aforementioned issues, FOBs are an ideal test case for renewable energy.

This paper develops two photovoltaic (PV)-battery storage system models of increasing realism and complexity that can be used to design an optimized system based on performance, cost and logistics. As a case study, these models will be applied to design a stand-alone PV replacement of a typical prime power generator used at military FOBs. This design will then be compared against existing diesel generators, examining the lifecycle cost and logistics requirements. If demonstrated to be workable, this PV design model can then be applied to other types of remote sites.

\section{LITERATURE SEARCH}

Previous research studies have examined: (1) hybrid and renewable systems for remote locations; (2) DoD use of renewable energy at FOBs; and (3) potential DoD prototypes of renewable systems. For hybrid and PV systems, previous research considered optimizations between PV and generators in non-military austere environments to include power systems utilizing wind and PV [6], diesel generator and PV hybrids [5], and PV only [6]. There is also a study comparing the weight of various types of PV panels for logistics analysis [9]. Perera et al. [10] examined a renewable hybrid system showing that, to minimize initial costs, when beginning the use of renewables it is optimal to add renewable components to existing nonrenewable systems. Therefore, for initial testing at remote locations, a potential renewable replacement should be modular, allowing it to be used in conjunction with other generators. For the purpose of this model and system design, the renewable energy resource is confined to $\mathrm{PV}$, as it is currently the fastest growing and most promising renewable technology for generator replacement at remote locations [11].

In the second category of studies, DoD-focused research has examined the economics and optimization of PV arrays and battery storage for use by the DoD. On the scale of a full-size base, Schill [2] investigated the advantages and difficulties of 12 possible energy sources. At a smaller scale ( $5 \mathrm{~kW})$, one study demonstrated a $36 \%$ savings of fuel is possible through battery-generator hybridization, thereby operating generators only at peak efficiency [12]. On the scale of a single FOB, Wagner et al. [13] published results of the time-phased nature of PV arrays and the optimum configuration both with and without batteries to replace entire FOB power grids. Furthermore, McCaskey [14] examined the supplementation of existing $750 \mathrm{~kW}$ MEP-12 generators with wind, solar and battery storage and proposes a test case at a base in New Mexico. His research focuses on optimizing the addition of renewables to existing generators in a hybrid form, instead of examining possible stand-alone replacements [14]. 
In the third category, other studies have begun to investigate the physical engineering requirements necessary to produce DoD-oriented renewable sources. The National Renewable Energy Laboratory (NREL) and the Air Force Research Laboratory (AFRL) designed and built a prototype for a mobile inverter and battery platform capable of converting renewable energy from solar or wind sources to supply AC power for FOBs [15]. AFRL's design supplies $30 \mathrm{~kW}$ of power-too small for a prime-power replacement, but still an advancement for hybrid energy use. From 2008 to 2012 AFRL also experimented with a variety of temporary shelter designs that incorporated integrated PV shades, improved insulation, and reconfigured HVAC systems to provide a 35-65\% reduction in energy demand [16].

Despite the significant contributions of the aforementioned research, these studies have not yet demonstrated a workable design of a stand-alone PV-energy storage replacement for prime-power generators at remote locations while considering cost and performance. Additionally, weight, volume, and shipping configuration of PV have been only cursorily examined but have a major impact on decisions to implement such systems. Accordingly, this paper presents the development of an optimization model for PV-battery systems, illustrating the key tradeoffs and logistics considerations involved and outlining a potential replacement system. Such a replacement solution could provide benefits for military FOBs, remote communities and other isolated sites.

\section{METHOD}

To develop and demonstrate a practical PV-battery storage system design and optimization model, it was necessary to select a specific requirement and location to model. For this study, the United States Air Force (USAF) Basic Expeditionary Airfield Resources (BEAR) Power Unit generator, known as a BPU, was selected to model for replacement. For location, a notional 1,100-personnel FOB in Afghanistan (similar to many other military environments) was chosen.

The BPU supplies $800 \mathrm{~kW}$ at $60 \mathrm{~Hz} 4160 / 2400 \mathrm{VAC}$ across a wide range of environmental conditions using diesel fuels [17]. Approximately 6-8 BPUs can supply a 1,100-personnel FOB with sufficient surplus generation available for generator downtime due to maintenance and repair [14]. The average load for a theoretical base of this size is 4.8 MW [14]. Prime power generators frequently operate at up to rated capacity for extended periods of time. Therefore, a replacement PV system must be capable of providing a consistent $800 \mathrm{~kW}$ for each removed BPU removed. However, PV arrays do not provide power at a constant rate, but instead the power produced changes depending on weather conditions and solar intensity [12]. Therefore, meeting a constant demand is difficult for PV systems. To offset the timephased nature of PV-supply, batteries are necessary to provide power when solar intensity is insufficient. While many other energy storage methods are possible, this paper focuses on developing an optimization model; therefore, the design assumption was confined to lithium-ion batteries.

Due to the remoteness of FOBs, it is often necessary to transport generators and other power system components long distances via air, ground, or sea transport. Given the practice of military operations, the USAF BPU is provided in a mobile, palletized configuration, enabling the transportation and setup of FOB power grids in a matter of days. Similarly, a renewable replacement system must keep transported size and weight to a minimum since all components of the power system may need to be airlifted to the remote location or FOB. The installed area required for a PV array compared to diesel generators is another factor since available land can be limited. While not the only factor, the initial purchase and ongoing system costs are important, so the total lifecycle cost was included in the model. 
Once a PV replacement system is designed using the model, its performance must be compared with current BPU generators. Performance was measured based on (i) lifecycle cost, (ii) total initial cost, (iii) ability to meet the power demand, (iv) system size, and (v) system weight. Key assumptions were that the lifecycle of the system is short enough that generator, battery, and PV panel degradation and replacement can be ignored. For the purpose of this study, the first few years of system lifecycle were considered. For the BPU, we assumed military forces will handle installation as part of base setup and the regular preventative maintenance costs are ignored. This makes the model slightly conservative by underestimating the generator costs.

In order to analyse and develop a model for the PV replacement system, certain parameters and assumptions are chosen, as shown in Table 1. Because weight and size are major concerns for the logistics of these remote sites, lithium ion batteries were selected in the design despite their higher cost. Generator fuel consumption is from the comparable $750 \mathrm{~kW}$ MEP-12 [18]. Costs shown in the table were adjusted to 2018 values using the US Bureau of Labor Statistics' CPI rates [19]. In order to model logistics considerations, Table 2 displays the estimated weights and volumes for each of the power system components.

The PV array panels are assumed to be $38 \mathrm{~mm}$ thick and stacked for shipment, providing an estimated energy density of $2.86 \mathrm{~kW} / \mathrm{m}^{3}$ for the PV array. Because weight density is also

Table 1: System cost and model parameters.

\begin{tabular}{lcc}
\hline Component & Parameter & Reference \\
\hline PV array cost (installed) & $\$ 1.50 / \mathrm{W}$ & Wagner et al. [13] \\
PV system losses & $15 \%$ & Wagner et al. [13] \\
PV panel efficiency (fixed, latitude-tilt) & $15 \%$ & Wagner et al. [13] \\
Inverter cost & $\$ 0.42 / \mathrm{W}$ & McCaskey [14] \\
Lithium ion battery system installed cost & $\$ 310 / \mathrm{kWh}$ & Diorio et al. [20] \\
Battery storage losses & $8 \%$ & Diorio et al. $[20]$ \\
Generator cost & $\$ 587 \mathrm{~K}$ & USAF [17] \\
Fuel consumption / generator efficiency & $55 \mathrm{gal} / \mathrm{hour}(750 \mathrm{~kW})$ & USAF [18] \\
& $=3.59 \mathrm{kWh} / \mathrm{L}$ & \\
Fully burdened cost of fuel & $\$ 4.69 / \mathrm{L}(\$ 17.74 / \mathrm{gal})$ & US GAO [3] \\
\hline
\end{tabular}

Table 2: Logistics performance parameters.

\begin{tabular}{lcc}
\hline Component & Parameter & Reference \\
\hline PV array deployed footprint & $9.29 \mathrm{~m}^{2} / \mathrm{kW}$ & McCaskey [14] \\
PV panel thickness & $38 \mathrm{~mm}(1.5 \mathrm{in})$ & - \\
PV array packed size & $0.35 \mathrm{~m}^{3} / \mathrm{kW}$ & - \\
PV array weight & $0.04 \mathrm{~kg} / \mathrm{W}$ & Yilmaz et al. $[9]$ \\
Weight of batteries & $10 \mathrm{~kg} / \mathrm{kWh}$ & Diorio et al. $[20]$ \\
Volume of batteries & $0.0287 \mathrm{~m}^{3} / \mathrm{kWh}$ & Diorio et al. $[20]$ \\
Weight of generator & $18,651 \mathrm{~kg}(41,118 \mathrm{lbs})$ & USAF [17] \\
Weight of fuel $(\mathrm{JP}-8)$ & $0.81 \mathrm{~kg} / \mathrm{L}(6.8 \mathrm{lbs} / \mathrm{gal})$ & - \\
\hline
\end{tabular}


a major factor for transport, thin-film silicon PV panels were selected due to their light weight [9].

\section{ANALYSIS}

For this project, we create simplified and detailed models of an energy system that can meet the constant $800 \mathrm{~kW}$ power requirement of the BPU. Insolation estimates for the selected location were obtained from the NREL Geospatial Toolkit [14]. Figure 1 shows the available ground solar insolation, which peaks at approximately $1.16 \mathrm{~kW} / \mathrm{m}^{2}$ and averages $0.24 \mathrm{~kW} / \mathrm{m}^{2}$.

This average solar density is used to calculate the area for a solar array that can produce $800 \mathrm{~kW}$ of power on average like the BPU generator, as shown in eqn (1). The calculated size of the array for an average $800 \mathrm{~kW}$ output is $26,233 \mathrm{~m}^{2}$.

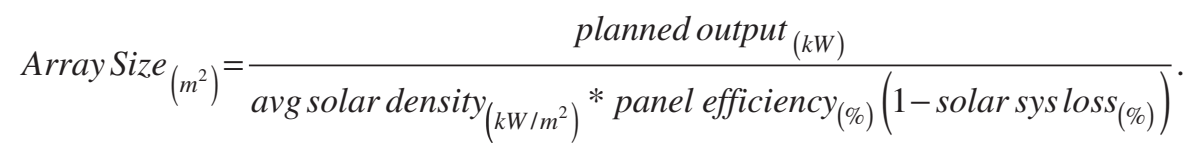

Using this solar data and an array size of $26,233 \mathrm{~m}^{2}$, the overall power production minus demand per hour at the hypothetical FOB was calculated (called excess power in this model) and is described by eqn (2).

$$
\begin{gathered}
\text { Excess Power }_{(k W)}=\text { ArraySize }_{\left(m^{2}\right)} * \text { insolation }_{\left(\frac{k W}{m^{2}}\right)} * \text { panel eff }_{(\%)} \\
\left(1-\operatorname{solarsysloss}_{(\%)}\right)-P_{\text {demand }} .
\end{gathered}
$$

where $P_{\text {demand }}=800 \mathrm{~kW}$.

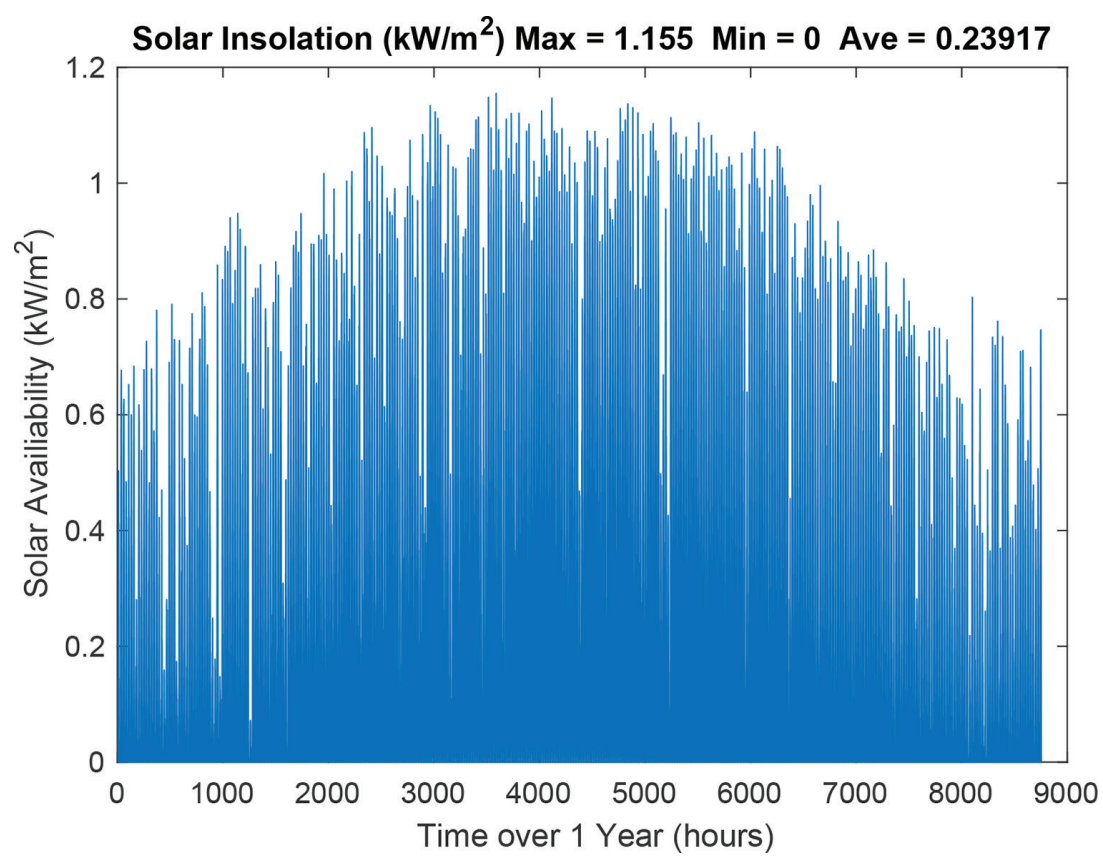

Figure 1: Notional FOB solar insolation. 


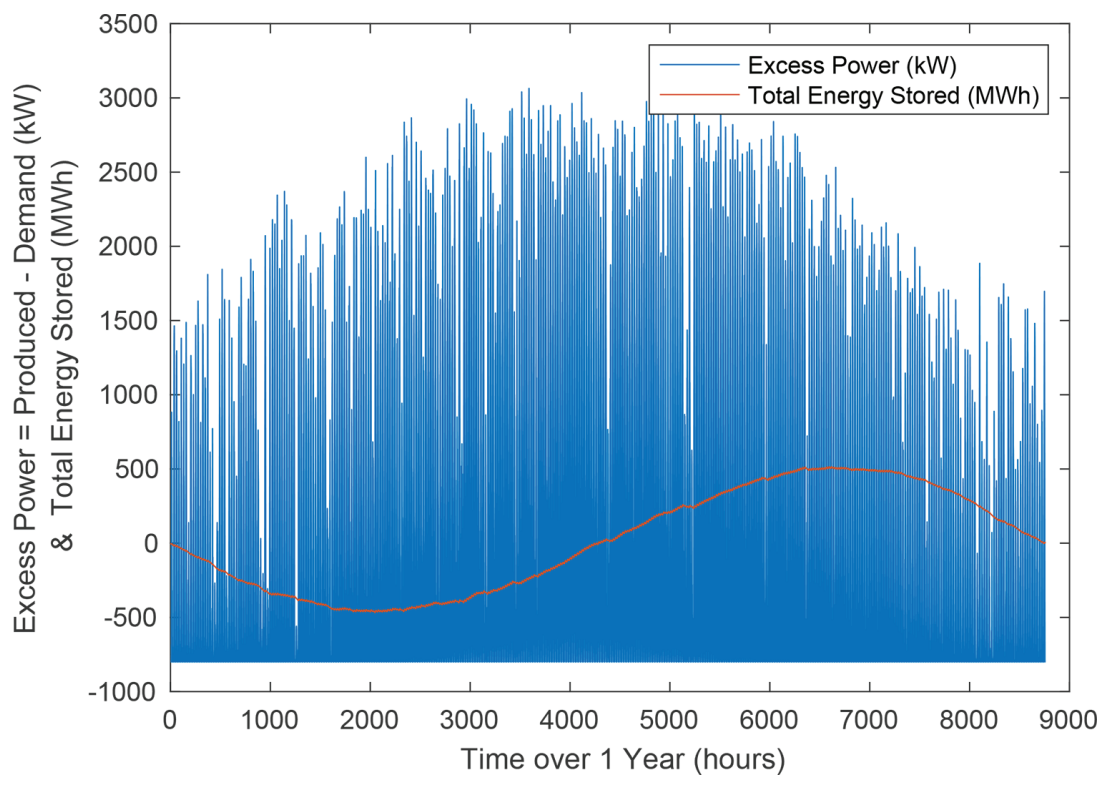

Figure 2: Power production and total energy stored over year.

Figure 2 shows the instantaneous power surplus or shortage (each hour) and the total energy surplus or deficiency stored, assuming unlimited storage. From this figure, we note that there are daily power shortages during hours of darkness, which will have to be repleted through battery storage or other production methods.

The energy stored is calculated by integrating the excess power (power produced minus the demand) over the year, as described in eqn (3). Because the battery losses and over/under charge conditions are not considered, this is only applicable to a simplified model.

$$
\text { Energy Stored }_{(k W h)}(t)=\sum_{t=0}^{8760}{\text { Excess } \text { Power }_{(k W)}}^{*} 1 \mathrm{hr} \text {. }
$$

The trough and peak of total energy stored show that a 470 MWh battery would be necessary to store enough power to meet the $800 \mathrm{~kW}$ demand during the darker, winter months. A battery this size would meet the demand for over 24 days without any power generation. At a rate of $\$ 310 / \mathrm{kWh}$ for energy storage, $\$ 146$ million is an unreasonable cost to replace a single generator. To reduce the size of the battery, additional solar panels can be added to provide additional power every day, reducing the required energy storage during winter months and cloudy days. By optimizing this PV array size and battery size combination, a much lower cost system can be achieved.

To conduct this optimization, a simplified MATLAB model was created using eqns (2)-(3) to simulate the PV-battery storage system, and a sweep of PV sizes ranging from $800 \mathrm{~kW}$ to $2,000 \mathrm{~kW}$ and battery sizes from 0 to $500 \mathrm{MW}$ was performed. Figure 3 shows this sweep along with excess energy produced by PV that is not required to meet the $800 \mathrm{~kW}$ demand. Through this two-variable optimization, $1,471 \mathrm{~kW}$ was found to be an ideal array size with an 11.6 MWh Li-Ion battery bank for minimum total system cost. With decreasing battery sizes, the overall cost of the system decreases rapidly until reaching the optimum cost point where the cost 


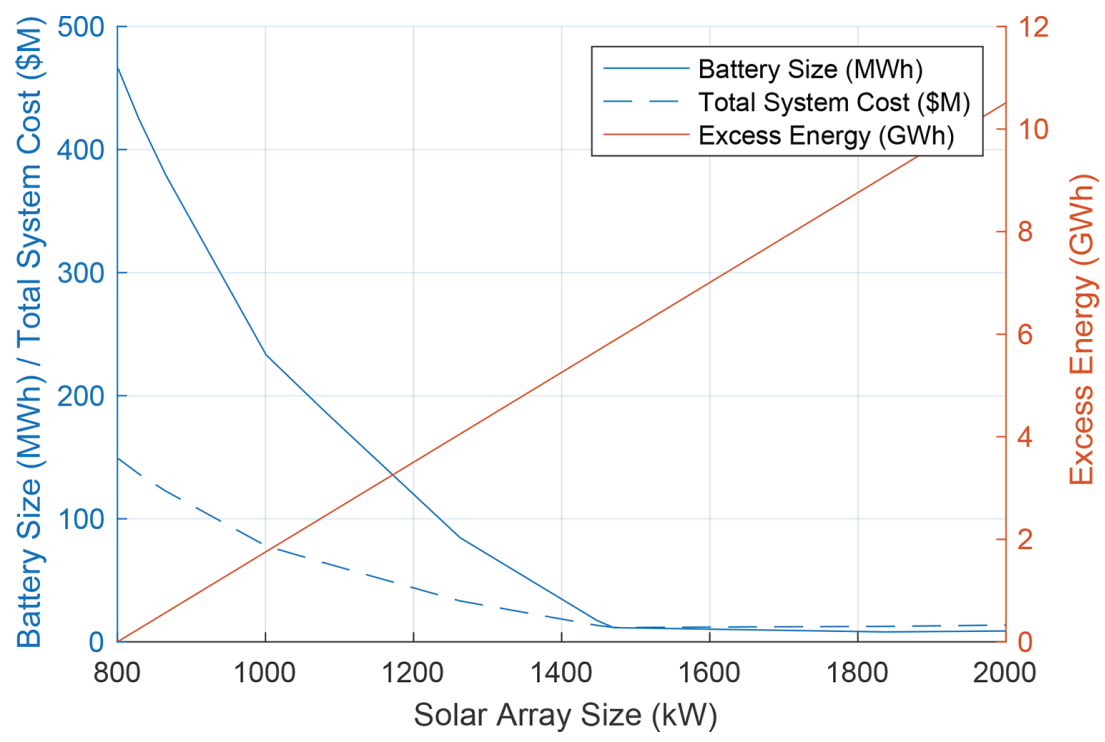

Figure 3: Simplified model system cost and battery vs. PV array sizes.

slightly rises as additional PV is added. The reason for this plateau is that the total system cost is impacted more by the battery costs than by the size of the PV array itself. It is crucial to note that this simplified model assumes a perfect battery with no over or under-charge energy losses. This is not realistic but was used for the initial approximation of optimum sizes for the system.

Next, a detailed model for the PV-battery system was created in the form of a MATLAB objective function, which we simulate to perform one- and two-variable optimizations. In this model, battery efficiency and over/undercharging losses from Table 1 were included. The objective function produced an output of the total cost and the hours that the system could not meet the required demand, by simulating a year of PV operation based on a given system size. Additonally, a penalty cost was added to the objective function output. The penalty cost places a dollar value on negative performance, such as when the system fails to meet the $800 \mathrm{~kW}$ demand. For this model, each hour (in a typical year) that the demand was not met was considered a $\$ 1,000$ additional cost, which is roughly equivalent to the fuel cost of running the BPU generator for an hour. The operation of this model is described in eqns (4)-(6).

$$
\begin{aligned}
& \text { Objective function }=f\left(\text { PVsize }_{k W}, \text { Battery Size }_{(k W h)}\right) \rightarrow \\
& \text { minimize }[\text { Penalty Cost }+ \text { Total System Cost }],
\end{aligned}
$$

where Penalty Cost $=(\$ 1,000 *$ Hours Not Met $)$.

Hours Not Met $=\sum_{t=0}^{8760 \overline{\bar{h}} r s}\left[\right.$ BattCharge $_{(k W h)}(t) \leq$ BattDepthOfDischarge $\left._{(k W h)}\right]$.

$\operatorname{BattCharge}_{(k W h)}(t+1)$

$$
\text { BattCharge }_{(k w h)}(t) \pm\left(1-\text { battLoss }_{\%}\right) * \text { ExcessPower }_{(k W)}(t+1) * \text { timestep. }
$$


Eqn (4) describes the goal of this model which is to minimize penalty cost based on battery and PV array size. Eqn (5) defines a loop that interates through an entire year of solar data ( 8,760 hours) to count the hours of failure criteria where the battery is completely discharged to the $10 \%$ minimum depth of discharge for the Li-Ion battery bank. Eqn (6) explains the battery charge/discharge model where the battery is charged when excess power is positive and discharges when it is negative. During the charge cycles the round-trip battery loss factor $\left(1-\right.$ battLoss $\left._{\%}\right)$ is applied. Not shown in this equation is MATLAB logic that also prevents overcharging the battery beyond $100 \%$ capacity.

Two sweeps of battery size and PV array size were completed, while holding the other parameter ( $\mathrm{PV}$ or battery, respectively) constant at the optimum size found in the previous optimization. In the detailed model, the key operational factor to consider is the failure condition or "Hours Demand Not Met". This parameter measures all the hours in a typical 8,760-hour year where the $800 \mathrm{~kW}$ demand would not be met and a power outage would occur. This scenario assumes the demand would require the full $800 \mathrm{~kW} 100 \%$ of the time, which is conservative.

The penalty costs are highly dependent on the chosen cost of each failure hour. At the $\$ 1,000 /$ hour penalty rate, penalty cost is not the best choice for system optimization as minimizing it results in over 2,000 hours of failure per year in the PV size sweep and 800 hours for the battery size sweep minimum penalty costs - at $23 \%$ and $9 \%$ failure rates, respectively, these are unacceptable levels of performance. Figure 4 shows the output sweep for PV sizes $0-5,000 \mathrm{~kW}$ with an 11.6 MWh battery.

The sweeps revealed that, at the current fixed battery/PV array size starting point, no optimum point of minimum total cost and failure hours is apparent; therefore, the optimization parameters were modified to enable optimization of both battery size and PV array size simultaneously.

A two-variable optimization was then performed using the detailed model to minimize the total cost and hours of failure. Because penalty cost failed to be an accurate representation of system performance, we instead minimize both system cost and failure hours, as shown in eqn (7). Figure 5 shows two surfaces comparing the resulting total cost and hours of failure for various battery and PV sizes.

Model 3 Objective $=f\left(\right.$ PVsize $_{k W}$, Battery Size $\left._{(k W h)}\right) \rightarrow \operatorname{minimize}[$ Cost, Hours Not Met $]$.

The upper right contour in the right subplot shows the area where no hours of failure occur. This chart clearly demonstrates the tradeoff between performance and cost.

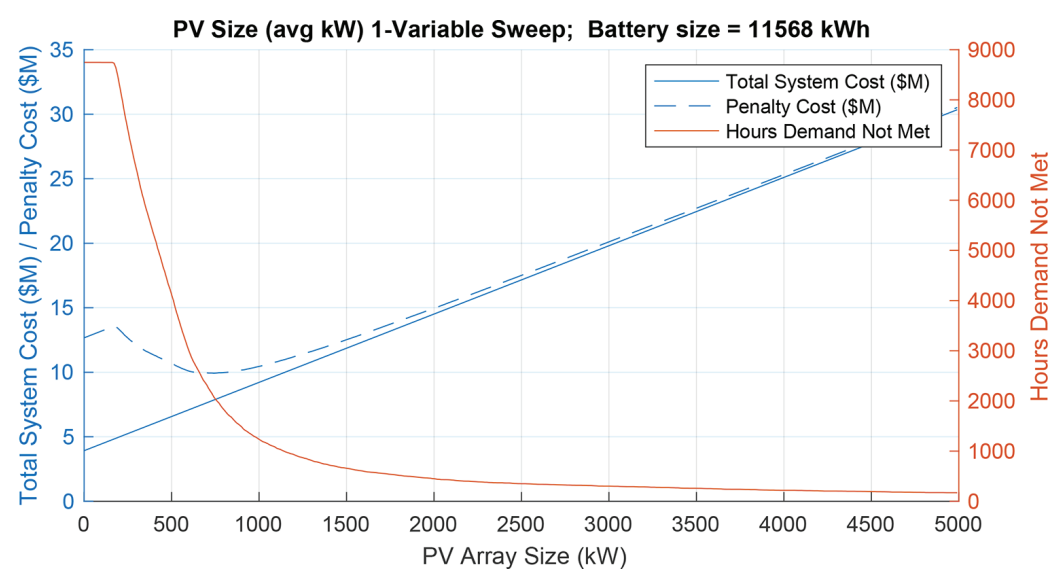

Figure 4: PV array size sweep with costs and hours not met (detailed model). 

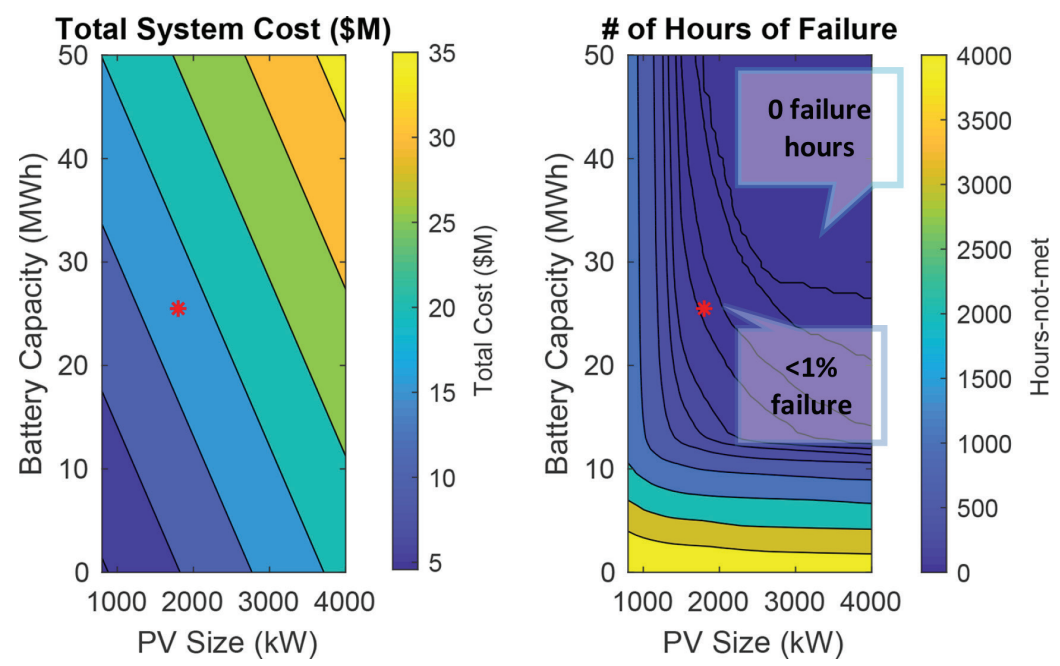

Figure 5: PV and battery size sweep with costs and hours not met. The red dot represents optimum cost point with $<1 \%$ failure rate.

As hours-not-met decreases, the total cost of the system increases rapidly. In comparison, the minimum system cost for no failure hours is $\$ 22.7 \mathrm{M}$ vs. $\$ 17.8 \mathrm{M}$ for a $1 \%$ failure rate.

For this system, a $1 \%$ failure rate is acceptable, as even generators have to allow downtime for maintenance and failures. At a $1 \%$ failure rate the optimum system size is $1,800 \mathrm{~kW}$ of PV array and 25.5 MWh for the battery size. This optimum size is plotted as a red point in Fig. 5 . At this optimum size, a solar year was plotted showing the instantaneous power and the battery charge. Figure 6 shows the time series generated PV power and battery state of charge for approximately 10 days of this year.

Figure 6 demonstrates a period during the winter months where two nights of power failure occur and the battery dips to minimum capacity at a $10 \%$ state of charge remaining. The solar input is significantly lower than normal, likely due to cloudy days. To get past these power shortages the FOB could run backup generators, reduce energy usage, or authorize using the batteries up to $100 \%$ depth of discharge, which is possible for a limited number of cycles for Li-ion batteries [12].

Using the component weights and volumes in Table 1, the total system shipping volume and weights were examined and compared against various battery and PV design sizes. The inverter weight and volume were considered negligible, which is reasonable [9]. Figure 7 shows this analysis with the same optimum system size again marked.

This analysis shows that system volume is impacted more by the size of PV array while the system weight is affected more by the battery capacity. At the $1 \%$ failure rate optimum system size, the total volume for PV array and batteries was found to be $3,000 \mathrm{~m}^{3}$ and the system weight $509,000 \mathrm{~kg}(1.12 \mathrm{M} \mathrm{lbs})$. These are roughly $50 \times$ larger and $27 \times$ heavier than the BPU that is $60 \mathrm{~m}^{3}$ and $18,651 \mathrm{~kg}(41,118 \mathrm{lbs})$. The fact that these quantities are much larger than the BPU is a significant logistical challenge, but not insurmountable, since this additional cargo required may be offset by the reduction in fuel used.

Finally, the lifecycle costs and logistics of both the PV + battery replacement system and the BPU were compared. To do this, a time series cost model was created to calculate energy system component cost and BPU fuel cost. The total weight transported, to include fuel, was also included. Figure 8 shows these results over a period of one year. 
Solar Year PV System Power -- PV size $=1800 \mathrm{~kW}$, Battery size $=25.5 \mathrm{MWh}$ Hours Demand Not Met $=85$

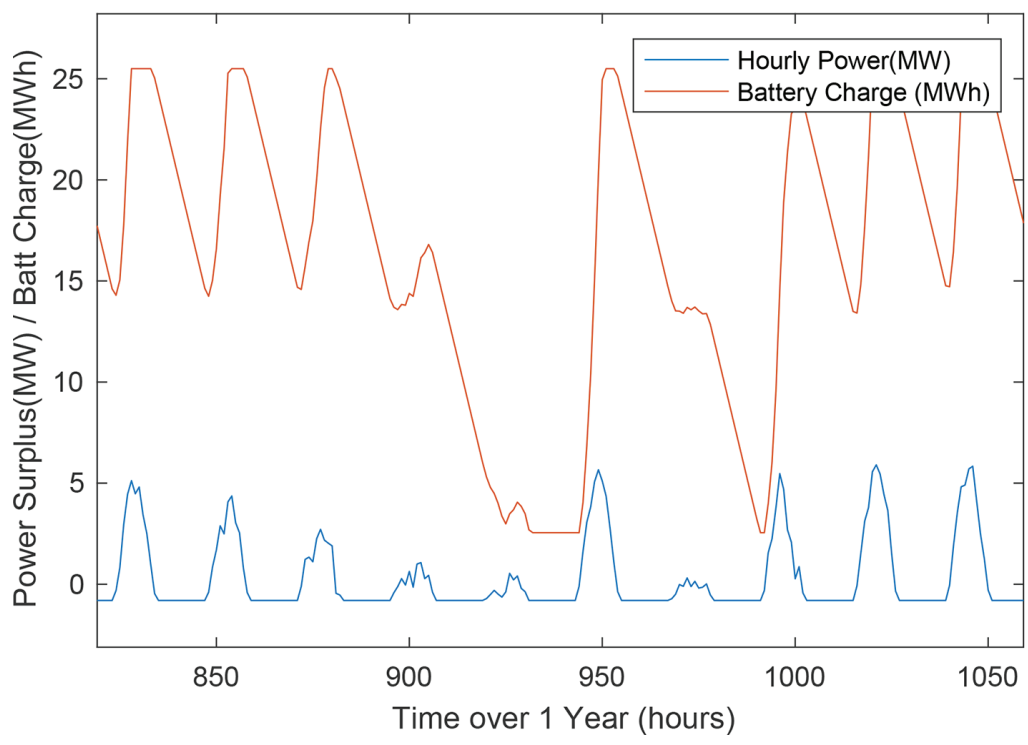

Figure 6: PV system power and battery charge over time.
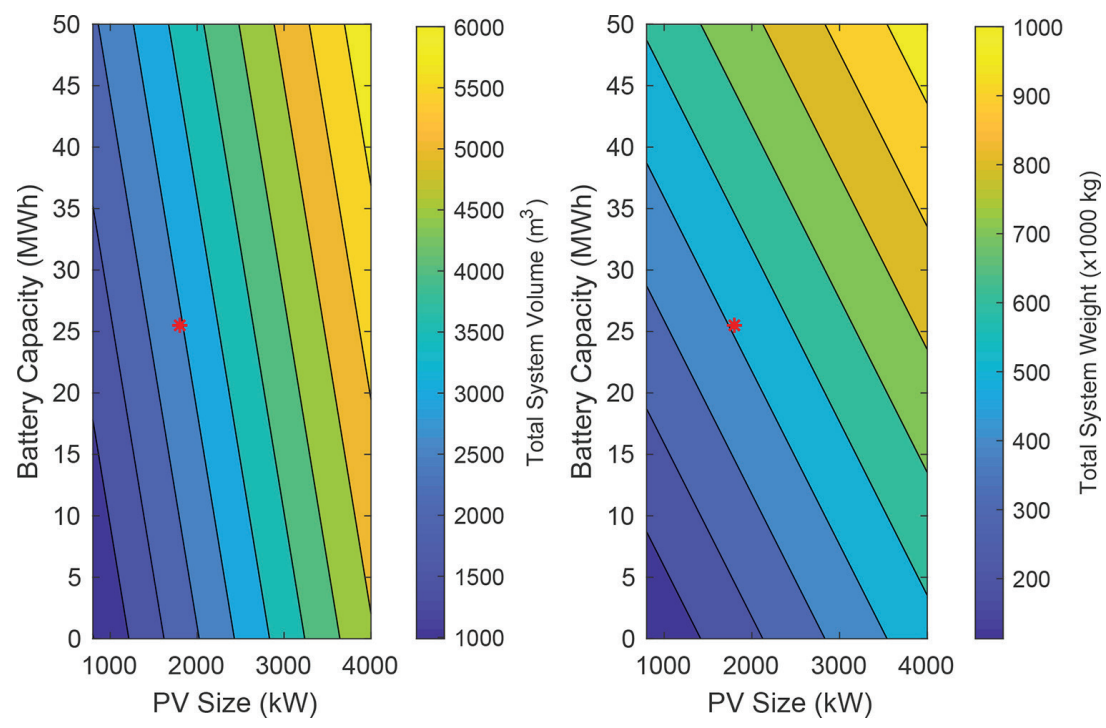

Figure 7: PV system transport volume and transport weight. Red point denotes previously optimized system size (for min cost and $<1 \%$ failure). 


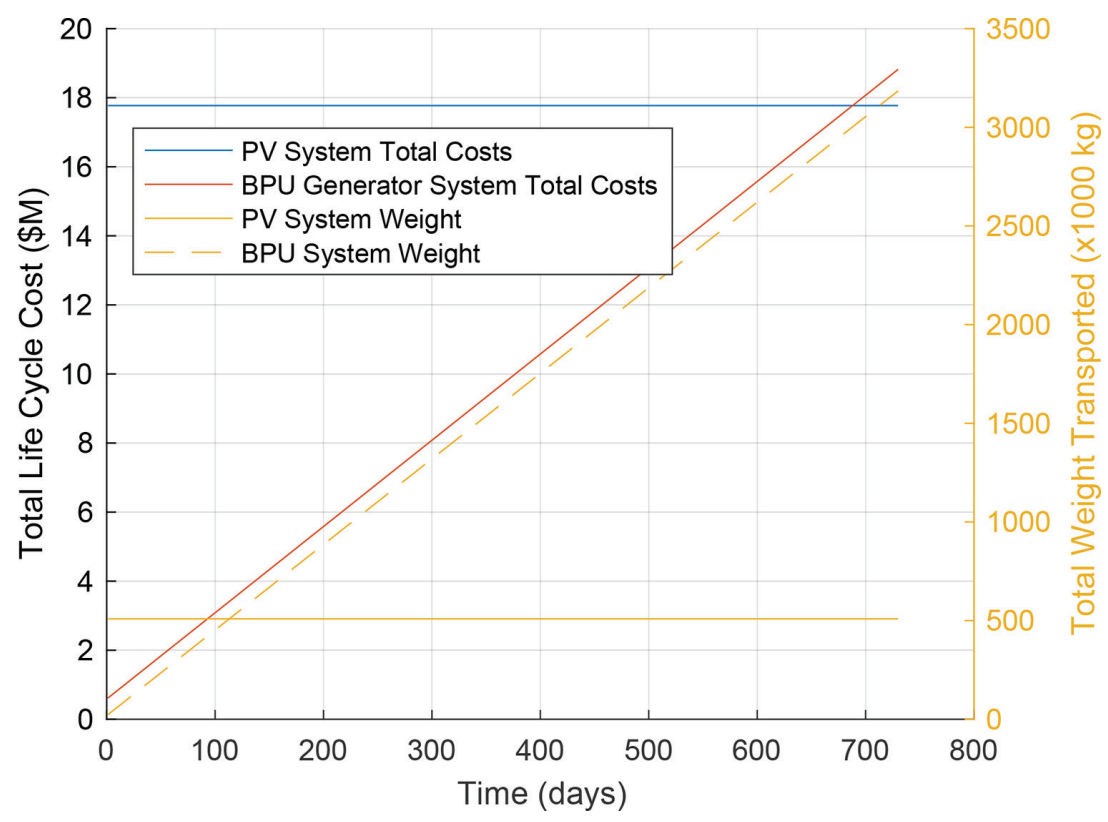

Figure 8: PV system and BPU lifecycle cost and transport weight.

This time series cost model demonstrates that, in spite of significantly higher initial cost, the renewable replacement system becomes cost-effective in a period of less than 700 days. While the PV system is 27 times heavier than the BPU, the total required transport weight for the PV replacement will be offset in just over 100 days by the weight of fuel.

\section{CONCLUSION}

This research has shown that a PV array and battery storage system could be a cost-effective replacement for diesel generators at remote locations as modelled by the $800 \mathrm{~kW}$ USAF BPU generator currently used at FOBs. The logistics required to transport these renewable replacement systems are substantial, but fuel savings quickly outweigh these initial challenges. If implemented, this PV system will reduce current military FOB reliance on diesel and reduce or eliminate the need for fuel convoys. Replacing a single diesel generator with the optimized case study system as modeled here would result in a savings of 1.9 million liters of fuel each year and eliminate the need for 100 fuel tanker deliveries. This study can easily be applied to other types of remote locations, enabling them to operate without continuous fuel resupply.

\section{REFERENCES}

[1] Arriaga, M., Canizares, C.A. \& Kazerani, M., Northern lights: Access to electricity in Canada's Northern and remote communities. IEEE Power and Energy Magazine, 12(4), pp. 50-59, July 2014.

[2] Schill, D., Improving energy security for air force installations. RAND Corp Santa Monica, CA, 2015.

[3] United States Government Accountability Office (US GAO), GAO-09-300 Defense Management: DOD Needs to Increase Attention on Fuel Demand Management at Forward-Deployed Locations. 2009. 
[4] Number, S., Chadwick, B. \& Mullins, J., Sustainable forward operating bases. Strategic Environmental Research and Development Program (SERDP). Noblis, 2015.

[5] Eady, D.S., Siegel, S.B., Bell, R.S. \& Dicke, S.H., Sustain the Mission Project: Casualty Factors for Fuel and Water Resupply Convoys. Army Environmental Policy Institute (AEPI), Arlington, VA, 2009.

[6] Saheb-Koussa, D., Haddadi, M. \& Belhamel, M., Economic and technical study of a hybrid system (wind-photovoltaic-diesel) for rural electrification in Algeria. Applied Energy, 86(7-8), pp. 1024-1030, 2009.

[7] Askarzadeh, A., Distribution generation by photovoltaic and diesel generator systems: Energy management and size optimization by a new approach for a stand-alone application. Energy, 122(1), pp. 542-551, March 2017.

[8] Akinyele, D., Analysis of photovoltaic mini-grid systems for remote locations: A technoeconomic approach. International Journal of Energy Research, 42(3), pp. 1363-1380, March 2018.

[9] Yilmaz, S., Ozcalik, H.R., Kesler, S., Dincer, F. \& Yelmen, B., The analysis of different PV power systems for the determination of optimal PV panels and system installationA case study in Kahramanmaras, Turkey. Renewable and Sustainable Energy Reviews, 52, pp. 1015-1024, December 2015.

[10] Perera, A.T.D., Attalage, R.A., Perera, K. \& Dassanayake, V., Designing standalone hybrid energy systems minimizing initial investment, life cycle cost and pollutant emission. Energy, 54, pp. 220-230, 2013.

[11] International Energy Agency, Renewables 2017: A New Era for Solar Power, 2017.

[12] Chester, D.J., Wagner, T.J. \& Dudis, D., 36\% reduction in FOB generator fuel use with optimized energy storage. Marine Corps Gazette, 103(3), 2019.

[13] Wagner, T., Lang, E., Assink, W. \& Dudis, D., Photovoltaic system optimization for an austere location using time-series data. Proceedings of the IEEE 45th Photovoltaic Specialists Conference, pp. 0-4, 2018.

[14] McCaskey, N.C., Renewable Energy Systems for Forward Operating Bases: A Simulations-Based Optimization Approach, Colorado State University, 2010.

[15] Kosowatz, J., Military Looks to Renewables in Battle Zones. ASME Online. https:// asme.org/engineering-topics/articles/energy/military-looks-renewables-battle-zones (accessed 14 October 2018).

[16] Keith, M.V., Moheisen, R.M., Shaaban, A.H. \& Salavani, R., Photovoltaic (PV) Integrated Power Shelter Systems for Basic Expeditionary Airfield Resources (BEAR), 2012.

[17] USAF, 635th Materiel Maintenance Group. Definitive Guide to BEAR Base Assets, 2017.

[18] USAF, Air Force Tactics, Techniques, and Procedures AFTTP3-32.34V5 - Contingency Electrical Power Production and Distribution Systems, 2017.

[19] U.S. Bureau of Labor Statistics, "CPI (Consumer Price Index).” Online https://bls.gov/ cpi/home.htm (accessed 18 November 2018).

[20] Diorio, N., Dobos, A. \& Janzou, S., Economic Analysis Case Studies of Battery Energy Storage with SAM. National Renewable Energy Laboratory, 2015. 